ACU Sağlık Bilimleri Dergisinin Cilt: 10, Sayı: 1, sayfa 67'de yayımlanan ilgili makalede, çalışmada kullanılan yöntem adının yanlışlıkla, çalışma ile ilgisiz başka bir ölçek olarak kullanılması ve makalede alıntı yapılan bir yayına atıfta bulunulmasının unutulması nedenleri ile yazarlar tarafından gerekli düzeltmeler yapılarak yazının düzeltilmiş halinin yeniden yayımlanmasına karar verilmiştir. Doğru hali aşağıdaki gibidir.

\title{
Bir Geçerlik ve Güvenirlik Çalışması: Öz-Yeterlik için Semptom Yönetim Ölçeği
}

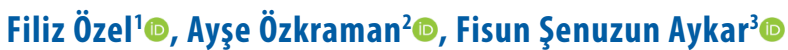

${ }^{1}$ Kastamonu Üniversitesi Sağlık Bilimleri Fakültesi, Hemşirelik, Kastamonu, Türkiye ${ }^{2}$ Eskişehir Osmangazi Üniversitesi Sağlık Bilimleri Fakültesi, Hemşirelik, Eskişehir, Türkiye

${ }^{3}$ Ege Üniversitesi Hemşirelik Fakültesi, Hemşirelik, İzmir, Türkiye

Filiz Özel, Dr. Öğr. Üyesi Ayşe Özkraman, Doç. Dr. Fisun Şenuzun Aykar, Prof. Dr.

İletişim:

Dr. Öğr. Üyesi Filiz Özel

Kastamonu Üniversitesi Sağlık Bilimleri Fakültesi, Hemşirelik, Kastamonu, Türkiye Tel: +903662804141

E-Posta: 0zelfiliz85@hotmail.com

Gönderilme Tarihi : 26 Nisan 2017

Revizyon Tarihi : : 06 Ağustos 2017

Kabul Tarihi : 11 Ağustos 2017
ÖZET

Amaç: Bu araştırmanın amacl; Öz-Yeterlik için Semptom Yönetim Ölçeği'nin Türkçe geçerlik ve güvenilirlik çalışmasını yaparak bu ölçeği ulusal literatüre kazandırmaktır.

Gereç-Yöntem: Araştırmada, 13 ifadeden oluşan Öz-Yeterlik için Semptom Yönetim Ölçeği kullanılmıştır. Öncelikle ölçeğin Türkçe geçerlik ve güvenilirlik çalışmalarının yapılabilmesi için dil ve kapsam geçerlikleri yapıımış, dil ve kapsam geçerlikleri sonucunda oluşan Türkçe ölçek; iki farkı hastanede tedavi gören kronik hastalığa sahip bireylere uygulanmışır. Bu uygulamadan elde edilen veriler, ilk olarak ölçeğin yapı geçerliğini test etmek adına yapısal eşitlik modeli kullanılarak değerlendirilmiş ve yine güvenilirlik testleri de bu veriler üzerinden gerçekleştirilmiştir.

Bulgular: Öz-Yeterlik için Semptom Yönetim öIçeği'nin Türkçe geçerlik ve güvenilirlik çalışması sonucunda iyi derecede uyum indekslerine sahip olduğu ( $\mathrm{X} 2=223,14, \mathrm{X} 2 / \mathrm{sd}=4.13, \mathrm{RMSEA}=0.077, \mathrm{CFI}=0.90, \mid \mathrm{FI}=0.91, \mathrm{NNFI}=0,90 \mathrm{ve} \mathrm{NFI}=0,91$ ); 1 boyut ve 12 sorudan oluştuğu ortaya konulmuştur.

Sonuç: Bu araştırmada, Öz-Yeterlik için Semptom Yönetim ÖIçeği'nin Türkçe versiyonu elde edilerek ulusal literatüre bu ölç̧ĕin kazandırılmıştır.

Anahtar sözcükler: Öz-yeterlilik, semptom yönetimi, kronik hastalıklar

\section{A THE VALIDITY AND RELIABILITY STUDY: THE SYMPTOM MANAGEMENT SCALEFOR SELF-EFFICACY}

\section{ABSTRACT}

Objective: The purpose of this study was to conduct the validity and reliability study of the Symptom Management Scale for Self-efficacy and to contribute to the national literature with this scale.

Materials-Methods: The study used the Symptom Management Scale for Self-efficacy. It has 13 items. The researcher primarily checked the language and content validity of the scale to do the validity and reliability studies of the scale in Turkish. Then, the Turkish scale, which was shaped by language and content validity studies, was administered to individuals with chronic diseases being treated in two hospitals. The collected data from this administration were evaluated using the structural equivalence model to test the construct validity of the scale. The reliability tests were also done with these data. Results: TheTurkish validity and reliability study of the Symptom Management Scale for Self-efficacy found that the scale had favorable fit indices ( $\mathrm{X} 2=223,14, \mathrm{X} 2 / \mathrm{SD}=4.13, \mathrm{RMSEA}=0.077, \mathrm{CFI}=0.90, \mathrm{IFI}=0.91, \mathrm{NNFl}=0.90$ and $\mathrm{NFI}=0.91$ ), and included one dimension and 12 questions.

Conclusion: This study prepared a Turkish version of the Symptom Management Scale for Self-efficacy and contributed to the national literature.

Keywords: Self-efficacy, symptom management, chronic diseases 
K ronik hastalıklar kişiden kişiye bulaşın olmadığ hastalıklar olup kalp-damar hastalıkları, kanser kronik solunum hastalıkları, diyabet, artrit gibi geriye dönüşümü olmayan hastalıklardır (1). Kronik hastalıklar nedeniyle her yıl 30-70 yaş arası 14 milyondan fazla insan yaşamını kaybederken, ülkemizde görülen ölümlerin \%86'ı bu hastalıklara bağlıdır (2). Kronik hastalıkların yönetiminde uygulanan tedavide hastanın hastalığını yönetebilmesi ile olumlu sağlık sonuçlarının elde edilmesinde hastanın kendi kendine yönetimi esastır $(3,4)$.

Kronik hastalıklarda kendi kendine yönetim, sağlık durumuna paralel fiziksel, psiko-sosyal ve yaşam tarzında meydana gelen değişiklikleri dikkate alarak birey, aile ve toplum tarafından sağlığı geliştirmek ve iyileştirmek, hastalıkları önlemek için yapılan girişimlerdir $(5,6)$. Yapılan bir meta analizde bireylerin kronik hastalık hakkında bilgi edindiklerini, sağlık gereksinimlerini üstlendiklerini, sağlığı geliştirmek için aktivitelerde bulunduklarını, hastalığın getirdiği günlük sorunları ve ihtiyaçları yönetebilmek için gerekli strateji, tedavi, bakım uygulamalarını öğrendiklerini yani uzmanlaştıkları belirtilmiştir (7). Her geçen gün hastaların semptomları kendi kendilerine yönetme uğraşlarına rağmen tüm kronik hastalığı olan bireylerde durum aynı değildir. Çünkü kendi kendine yönetim fizyolojik, psikolojik, sosyal, demografik, gelişimsel farklılıklar ve tıbbi hizmetlerin erişilebilir olmasından etkilenmektedir (7-10). Bu durum öz yeterliğin etkili olduğu olumlu davranışların sürdürüldüğü hastalarda daha belirgindir (11-14).

Öz yeterlik bireyin istediği amaca ulaşmak için gerekli olan görevleri yerine getirmede kendisine duyduğu güveni belirtir (15). Genellikle bireyin kendi bildirimine dayalı ölçeklerle değerlendirilir. Öz yeterliliğin değerlendirilmesi için geliştirilen ölçek çalışmalarından bazıları kronik hastalık yönetimi, günlük yaşam aktivitelerinin yönetimi, tedavi yönetimi, semptom yönetimi, belirli bir hastalığın yönetimi gibi konuları ele almaktadır (16-23). Ülkemizde geçerlik güvenirlik aşamalarına uygun şekilde yapılan çalışmalarla bu ölçeklerden bazıları Türkçe literatüre kazandırılmıştır (24-29).

Kronik hastalıklarda hastaların öz bakımlarını gerçekleştirebilmeleri ve normal yaşam süreçlerine devam edebilmelerinde öz yeterlik hayati öneme sahiptir. Bu nedenle kronik hastalıklarda semptom yönetiminde öz yeterliliğin değerlendirilmesinin önemli olduğu düşünülmüş ve bu araştırmada Türkçe literatüre Öz-Yeterlik için Semptom Yönetim Ölçeği'nin (21) kazandırılması amaçlanmıştır.

\section{Gereç ve yöntem}

Araştırmanın amacı ve tipi: Araştırma Öz-Yeterlik için Semptom Yönetim Ölçeği'nin geçerlik ve güvenirliğini belirlemek amacıyla yapılan metadolojik bir araştırmadır.
Araştırmanın yapıldığı yer ve zaman: Araştırma etik kurul ve kurum izinlerini takiben Ocak 2016-Ocak 2017 tarihleri arasında bir devlet ve bir üniversite hastanesi olmak üzere iki hastanede yürütülmüştür.

Araştırmanın evren ve örneklemi: Araştırmanın evrenini izin alınan bir devlet ve bir üniversite hastanesinin İç Hastalıkları Polikliniği, Göğüs Hastalıkları Polikliniği, Kardiyoloji Polikliniği, Medikal Onkoloji Polikliniği, Endokrinoloji polikliniğine kayıtlı $(n=1500)$; kronik hastalık nedeniyle takip ve tedavi edilen hastalar oluşturmuştur. Araştırmanın örneklemi belirtilen evren içerisinde bilinç düzeyi açık; Türkçe konuşabilen ve araştırmaya katılmayı kabul eden hastalardan oluşmaktadır $(n=130)$.

Veri toplama araçları: Veriler, araştırmacılar tarafından ölçeğin geçerlik ve güvenirliği yapılması amacıyla"Semptom Yönetimi için Öz-Yeterlik Ölçeği" ve Birey tanıtım formu aracılığı ile toplanmıştır.

Birey tanıtım formu: Araştırmacılar tarafından ilgili literatür araştırılarak hazırlanan bu form, hastaların sosyo-demografik özelliklerine ilişkin 10 sorudan oluşmaktadır.

Öz-Yeterlik için Semptom Yönetim Ölçeği: Kronik hastalıklarda başarılı semptom yönetiminin bireyin yaşam kalitesinin arttırılması kadar hastaların öz bakımlarını yapabilmeleri ve normal yaşam süreçlerine devam edebilmelerinde hayati öneme sahip bir strateji olduğu düşünülmüş ve semptom yönetiminin değerlendirilmesinin önemli olduğu öngörülmüş ve ölçeğin kronik hastalıkların semptom yönetiminde geçerli ve güvenilir bir ölçek olduğu belirtilmiştir. Öz-Yeterlik için Semptom Yönetim Ölçeği'nin orjinali 13 maddeden ve bir alt gruptan oluşmaktadır. Maddeler 10 puanlı Likert tipi ölçek ile puanlandırılmıştır (0: Hiç emin değilim, 10: Tamamen eminim). Ölçekten alınabilecek toplam puan 13-130 arasında değişmektedir. Toplam değer 13-59 arasında ise düşük öz-yönetim, 60114 arasında ise orta derecede öz-yönetim ve 115-130 arasında ise yüksek öz-yönetim olarak değerlendirilmelidir (21). Araştırma kapsamında sırasıyla ölçeğin Dil Geçerliği, Kapsam Geçerliği ve Yapı Geçerliği incelenmiş olup son olarak ölçeğin güvenilirlik değerleri test edilmiştir (30). Araştırmada toplam katılımcı sayısı, ölçek ifadelerinin 10 katı şeklinde belirlenerek 130 olmuştur.

Araştırma Etiği ve İzinler: Ölçeğin araştırma için kullanımı konusunda Cicerone K.D. ile Nisan 2015 tarihinde e-mail yoluyla iletişim kurulmuş ve ölçeğin uyarlanabileceğine ilişkin gerekli izin alınmıştır. Bundan sonra araştırmanın yapılabilmesi için etik kurul ve hastanelerden izinler 
alınarak araştırma yürütülmüştür. Aynı zamanda, katılımcılara araştırmanın amacı, yararları açıklanmış, gönüllülük ilkesine özen gösterilerek yazılı onamları da alınmıştır.

\section{Bulgular}

Araştırmaya katılan hastaların \%84.4'ünün 60 yaşüstünde, \%51.6'sının erkek, \%89.1'inin evli, \%65.6'sının ilköğretim mezunu, \%84.4'ünün çalışmadığı ve \%54.7'sinin orta düzeyde gelire sahip olduğu saptanmıştır. Hastaların hastalık durumları incelendiğinde; \%32.8'inin kanser, \%26.6'sının kalp yetmezliği, \%15.6'sının diyabet, \%9.4'ünün hipertansiyon ve Kronik ObstruktifAkciğer Hastalığı (KOAH), \%4.7'sinin Serebrovasküler Olay (SVO) ve \%1.6'sının epilepsi tanısına sahip olduğu belirlenmiştir. Hastaların hastalık süreleri incelendiğinde ise; \%39.1'inin bir-beş yıl, \%22'sinin bir yıldan az, \%17.2'sinin altı-on yıl ve \%9.4'ünün on bir yıldan fazla olduğu belirlenmiştir. Hastaların \%75'inin günlük yaşam aktivitelerini bağımsız yapabildiği saptanmıştır. Ayrıca hastaların \%73.4'ünün hastalık yönetimini kendisinin yapabildiğini ifade ettiği saptanmıştır.

\section{Semptom yönetimi için Öz-Yeterlik Ö/çeği'nin dil geçerliği}

Ölçeğin dil geçerliği aşamalarında, ölçeğin kullanımıyla ilgili gerekli izinler alındıktan sonra, ilk olarak ölçeğin İngilizce orijinal metni; Türkçe'ye çevrisi için iki Türk öğretim üyesi ve 1 yeminli tercümana; Ingilizce'ye çevirisi için de üç Türkçe bilen ve konuşan öğretim üyesine gönderilmiştir. Çevirileri yapan öğretim üyeleri kronik hastalıklar ve semptom yönetimi konularına hakimdir. Elde edilen bu üç farklı çeviride Türkçe kullanıma uygun olmadığı tespit edilen ifadeler ise tekrar gözden geçirilerek revize edilmiş ve sonunda Türkçe ölçeğin son şekli elde edilmiştir.

\section{Semptom yönetimi için Öz-Yeterlik Ölçeği'nin kapsam (İçerik) geçerliği}

Dil geçerliği neticesinde elde edilen Türkçe ölçeğin son şekli, Kapsam (icçerik) geçerliği için konuyla ilgili alanlarında uzman toplam dokuz uzmanın bilgi ve görüşlerine sunulmuştur. Kendilerinden, ölçekte yer alan maddelerin konuyla ilgi olup olmadığı ve bu ölçekte yer alan her bir ifadenin anlaşılır olup olmadığı konusunda görüşler istenmiştir. Uzmanlardan, ölçekte yer alan her bir ifadeyi (ilişki, basitlik, anlaşılırlık) skalalarından oluşan üçlü derecelendirme formu kullanılarak değerlendirmeleri istenmiştir. Toplam 9 uzmandan gelen görüşlerin değerlendirilmesinde, her bir maddeye ait kapsam geçerliği oranı (KGO) hesaplanmıştır. Ardından, hesaplanan KGO'ların ortalaması alınarak kapsam geçerliği indeksi (KGi) belirlenmiştir. Bu indeks her bir madde için uzmanların o maddeyi gerekli görüp görmediklerinin belirlenmesinde kullanılmaktadır. Bu değer, maddelerin uygunluk düzeyi için hesaplanmıştır. $a=0,05$ anlamlılık düzeyinde, uzman sayısı 9 olması sebebiyle 0,59'dan büyük olan $\mathrm{KGO}$ değerine sahip maddelerin kapsam geçerliğinin sağlandığı sonucuna varılmıştır (30). Tüm maddelere ait KGi 1 olduğu için tüm maddelerin ölçekte kalmasına karar verilmiştir.

Semptom yönetimi için Öz-Yeterlik Ö/çeği'nin yapı geçerliği Semptom Yönetimi için Öz-yeterlik Ölçeğinin yapı geçerliğinin belirlenmesi amacıyla açımlayıcı faktör analizi (AFA), doğrulayıc faktör analizi (DFA)yapılmıştır. Ölçeğin yapı geçerliğini istatistiksel olarak tespit etmek için AFA tekniği kullanılmıştır. Ölçeğin öncelikli olarak, faktör analizine uygun olup olmadığını anlamak amacıyla KMO ve Bartlett testi yapılmıştır. Bu kapsamda Kaiser-Meyer-Olkin (KMO) testi ölçüm sonucunun 0.50 ve daha üstü, Bartlett küresellik testi sonucunun da istatistiksel olarak anlamlı olması gerekmektedir (31). Bu çalışma sonucunda KMO testi sonucu 0.79, Bartlett küresellik testi de $(p<0.01)$ anlamlı bulunmuştur. Buna göre, değişkenler arasında yüksek korelasyonlar mevcuttur, başka bir deyişle veriler faktör analizi için uygun bulunmuştur (32). illk analizde, öz değeri 1'den büyük olan 4 faktör olduğu belirlenmiştir. Ancak Şekil 1 incelendiğinde, öz değeri diğer faktörlerden daha yüksek olan ve açıkladığı varyansı daha yüksek olan tek faktörün baskın olduğu anlaşılmaktadır.

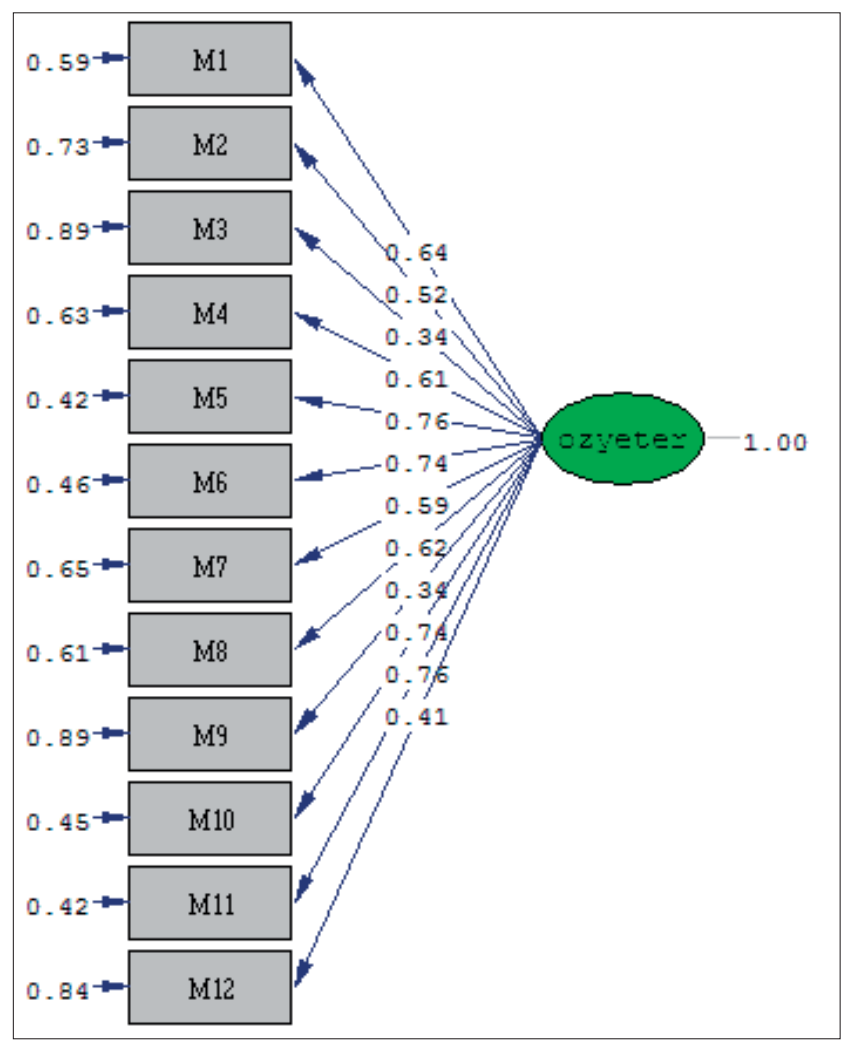

Şekil 1. Semptom yönetimi için Öz-Yeterlik Ölçeği'ne ait doğrulayıcı faktör analizi modeli 


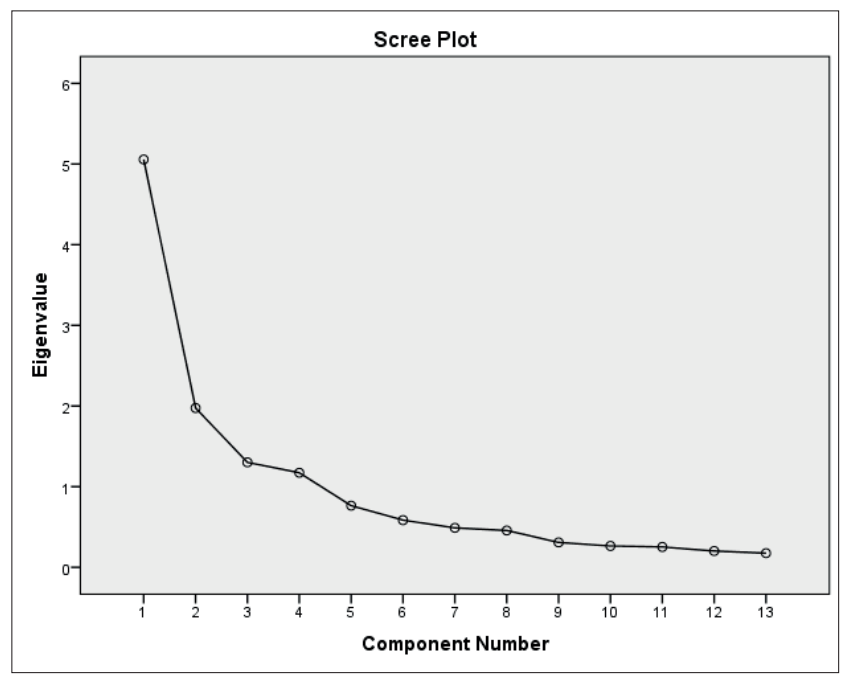

Grafik 1. Semptom yönetimi için Öz-Yeterlik Ölçeği'ne ait faktör grafiği

Açımlayıc faktör analizinde maddelerin yer aldıkları faktördeki yük değerleri için sınır değer 0.30 olarak alınmıştır. Faktör yük değeri 0.30'un altında olan maddeler analizden çıkartılmalıdır. Bu nedenle 13. madde ölçekten çıkartılmıştır. Nihai analiz sonunda Semptom Yönetimi için Öz-yeterlik Ölçeğinin AFA'ne ilişkin bulguları Tablo 1'de gösterilmiştir.

Tablo 1. Semptom yönetimi için Öz-Yeterlik Ölçeğ'’’nin faktör yüklerinin dağıımı

\begin{tabular}{lc} 
Maddeler & Faktör-1 \\
\hline M5 & 0,776 \\
M6 & 0,775 \\
M11 & 0,767 \\
M10 & 0,737 \\
M8 & 0,697 \\
M4 & 0,671 \\
M1 & 0,669 \\
M7 & 0,636 \\
M2 & 0,588 \\
M3 & 0,428 \\
M12 & 0,423 \\
M9 & 0,413
\end{tabular}

Semptom Yönetimi için Öz-yeterlik Ölçeğine yapılan AFA sonucunda ölçeğin tek faktörlü olduğu sonucuna varılmıştır. Bu faktör ölçeğe ilişkin toplam varyansın \%41.68'ini açıklamaktadır. Yapılan faktör analizi sonucunda elde edilen veriler ölçeğin geçerliğinin yüksek düzeyde olduğuna işaret etmektedir.
Ölçeğin faktör yapısının doğrulanıp doğrulanmadığı birinci düzey doğrulayıcı faktör analizi (DFA) ile incelenmiştir. DFA, pek çok gözlenebilir değişkenin oluşturduğu faktörlerden (gizil değişkenlerden) oluşan faktöryel bir modelin gerçek verilerle ne derece uyum gösterdiğini değerlendirmeyi amaçlamaktadır. İncelenecek model, ampirik bir çalışmanın verileri kullanılarak belirlenmiş ya da belirli bir kurama dayandırılarak kurgulanmış bir yapıyı tanımlayabilir (33). DFA'da modelin geçerliliğini değerlendirmek için çok sayıda uyum indeksi kullanılmaktadır. Bunlar içinde en sık kullanılanları (33,34); Ki-Kare Uyum Testi (Chi-SquareGoodness, $x^{2}$ ), Yaklaşık Hataların Ortalama Karekökü (RootMeanSquareError of Approximation, RMSEA), Karşılaştırmalı Uyum İndeksi (ComparativeFıt Index, CFI), Normlaştııımamış Uyum İndeksi (NonNormed Fit Index, NNFI), Normlaştırılmış Uyum İndeksi (Normed Fit Index, NFI), Iyilik Uyum İndeksi (Goodness of Fit Index, GFI). Ölçek modelinde gözlenen değerlerin $\mathrm{X} 2 / \mathrm{d}<3 ; 0<\mathrm{RMSEA}<0.05 ; 0.97 \leq \mathrm{NNFI} \leq 1 ; 0.97 \leq \mathrm{CFI} \leq 1$; $0.95 \leq \mathrm{GFI} \leq 1$ ve $0.95 \leq \mathrm{NFI} \leq 1$ aralıklarında olması mükemmel uyumu; $4<\mathrm{X} 2 / \mathrm{d}<5 ; 0,05<\mathrm{RMSEA}<0.08 ; 0.95 \leq \mathrm{NNFI} \leq 0.97$; $0.95 \leq \mathrm{CFI} \leq 0.97 ; 0.90 \leq \mathrm{GFI} \leq 0.95$ ve $0.90 \leq \mathrm{NFI} \leq 0.95$ ise kabul edilebilir uyumu göstermektedir $(33,35)$.

Bu bölümde, ölçeğin tek boyutuna ait 12 maddelik yapısının doğrulanıp doğrulanmadığını değerlendirmek amacıyla DFA uygulanmıştır. Uygulanan ilk DFA'da istatistiksel olarak anlamlı olmayan t değerine sahip maddeler incelenmiştir. Bu ölçeğe ait tüm $t$ değerleri anlamlıdır. Doğrulayıcı faktör analizi modeli Şekil 1'de yer almaktadır. Uyum indeksleri $X^{2}=223,14, X^{2} / s d=4.13$, RMSEA $=0.077$, $\mathrm{CFI}=0.90, \mathrm{IFI}=0.91, \mathrm{NNFI}=0,90$ ve $\mathrm{NFI}=0,91$ olarak bulunmuştur. Bu ölçeğin faktöryel yapısını gösteren modelin gözlenen değişkenleriyle faktörleri arasındaki ilişkiyi gösteren katsayılar incelendiğinde, tüm katsayıların yeterli düzeyde olduğu sonucuna varılmıştır. DFA ile hesaplanan uyum istatistikleri dikkate alındığında, ölçeğin daha önce belirlenen yapısının toplanan verilerle genel olarak uyum sağladığına karar verilmiştir.

Maddelere ait regresyon değerleri ve $t$ değerlerine Tablo 2'de yer verilmiştir. Tablo 2 incelendiğinde, elde edilen regresyon katsayılarının ve $t$ değerlerinin anlamlı olduğu $(t>1,92)$ ve modelin doğrulandığı belirlenmiştir.

\section{Semptom yönetimi için Öz-yeterlik Ölçeği'nin güvenilirlik analizleri}

Çalışma kapsamında kullanılan Semptom Yönetimi için Özyeterlik Ölçeği'nin güvenilirliğini test etmek için; özellikle, toplam puanlar üzerine kurulu likert tipi ölçeklerin güvenilirliğini hesaplamada sıklıkla kullanılan ve iç tutarlıık katsayısı olarak ifade edilen cronbach alpha (a) değerlerinin yanı 
Tablo 2. Semptom yönetimi için Öz-Yeterlik Ölçeği'ne ait regresyon ve $T$ değerleri

\begin{tabular}{lcc} 
Maddeler & Regresyon değerleri & T değerleri \\
\hline M1 & 0,64 & 7,74 \\
M2 & 0,52 & 6,02 \\
M3 & 0,34 & 3,73 \\
M4 & 0,61 & 7,27 \\
M5 & 0,76 & 9,87 \\
M6 & 0,74 & 9,35 \\
M7 & 0,59 & 6,99 \\
M8 & 0,62 & 7,51 \\
M9 & 0,34 & 3,74 \\
M10 & 0,74 & 9,46 \\
M11 & 0,76 & 9,76 \\
M12 & 0,41 & 4,56
\end{tabular}

sıra yapısal güvenilirlik olarak da ifade edilen McDonald'ın omega $(\omega)$ katsayısı, ölçeğin tamamı için hesaplanmıştır. Cronbach Alfa güvenirlik katsayısı için yapılan istatistiklerde ölçeğin alfa değeri 0.86 olarak belirlenmiştir. McDonald'ın omega katsayısı ise 0.98 olarak bulunmuştur. Tezbaşaran (1997), likert tipi bir ölçekte yeterli sayılabilecek bir güvenirlik katsayısının olabildiğince 1'e yakın olması gerektiğini ifade etmektedir (36). Bu sonuçlara göre ölçeğin istatistiki olarak güvenilir söylenebilmektedir.

\section{Tartışma ve sonuç}

Bu araştırmanın amacl; Semptom Yönetimi için Özyeterlik Ölçeği'nin Türkçe geçerlik ve güvenilirlik

\section{Kaynaklar}

1. World Health Organization (WHO). Noncommunicable diseases. Update 2017. Available from http://www.who.int/topics/ noncommunicable_diseases/en/

2. World Health Organization (WHO). Non communicable diseases country profiles 2014. 2014b:

3. Nolte E, Knai C, McKee M. Managing chronic conditions experience in eight countries. World Health Organization 2008, on behalf of the European Observatory on Health Systems and Policies. ISBN:978 92 8904294 9. p.1-5.

4. Chen MF, Wang RH, Lin KC, Hsu HY, Chen SW. Efficacy of an empowerment program for Taiwanese patients with type 2 diabetes: A randomized controlled trial. Appl Nurs Res 2015;28:366-73. [CrossRef]

5. World Health Organization (WHO). Health education in self care: Possibilities and limitations. Report of a Scientific Consultation 1983;21-25 November: Available from http://apps.who.int/iris/ bitstream/10665/70092/1/HED_84.1.pdf çalışmasını yaparak bu ölçeği ulusal literatüre kazandırmaktır. Araştırmada, kronik hastalığa sahip hastaların öz yeterliklerini belirleyen bir boyut ve toplam 13 ifadeden oluşan "Semptom Yönetimi için Öz-yeterlik Ölçeği" kullanılmıştır. Öncelikle ölçeğin Türkçe geçerlik ve güvenilirlik çalışmalarının gerçekleştirilebilmesi için dil ve kapsam geçerlikleri yapılmış, dil ve kapsam geçerlikleri neticesinde ortaya çıkan Türkçe ölçek; bir devlet ve bir üniversite hastanesinde İç Hastalıkları Polikliniği, Göğüs Hastalıkları Polikliniği, Kardiyoloji Polikliniği, Medikal Onkoloji Polikliniği, Endokrinoloji polikliniklerine kronik hastalığa sahip bireylere uygulanmıştır. Bu uygulama neticesinde elde edilen veriler, ilk olarak ölçeğin yapı geçerliğini test etmek adına yapısal eşitlik modeli kullanılarak değerlendirilmiş ve yine güvenilirlik testleri de bu veriler üzerinden gerçekleştirilmiştir. Ölçeğin doğrulayıcı faktör analizi sonuçlarına bakıldığında; ölçeğe ait ilişkili bir faktörlü yapı çerçevesinde elde edilen veri-model uyum indekslerinin $\left(X^{2}=223,14, X^{2} / s d=4.13\right.$, RMSEA $=0.077, C F I=0.90,|F|=0.91$, $\mathrm{NNFI}=0,90$ ve $\mathrm{NFI}=0,91)$ uyum için gerekli asgari düzeyi karşıladığı görülmektedir. Ölçeğin güvenilirliğini test etmek için; likert tipi ölçeklerin güvenilirliğini hesaplamada sıklıkla kullanılan ve iç tutarlılık katsayısı olarak ifade edilen cronbach alpha (a) değerleri ve konjenerik ölçümlerin güvenilirlik hesaplamaları için önerilen McDonald'ın omega $(\omega)$ katsayısı hesaplanmış ve bu hesaplamalar sonucunda ölçeğin yüksek derecede güvenilir olduğu bulunmuştur. Sonuçta, Semptom Yönetimi için Öz-yeterlik Ölçeği'nin Türk toplumu için geçerlik ve güvenirliğinin incelendiği bu araştırmada, uyarlama çalışmaları uluslararası bilimsel yöntemlere uygun olarak yapılmış ve ölçeğin Türkçe formunun geçerlik ve güvenirlik ölçütlerini karşıladığı belirlenmiş̧tir.

6. Richard AA, Shea K. Delineation of self-care and associated concepts. J Nurs Scholarsh 2011;43:255-64. [CrossRef]

7. Schulman-Green D, Jaser S, Martin F, Alonzo A, Grey M, McCorkle $R$, et al. Processes of self-management in chronic illness. J Nurs Scholarsh 2012;44:136-44. [CrossRef]

8. Bahouq H, Rkain H, Allali F, Hassouni NH. Self esteem in patients with ankylosing spondylitis and its relationships with disease-specific variables and psychological status. Ann Rheum Dis 2013;71:562-3. [CrossRef]

9. Oksman E, Linna M, Hörhammer L, Lammintakanen J, Talja M. Costeffectiveness analysis for a tele-based health coaching program for chronic disease in primary care. BMC Halth Serv Res 2017;17:138. [CrossRef]

10. Lorig K, Ritter PL, Moreland C, Laurent DD. Can a box mailed materials achieve the triple aims of health care? The mailed chronic disease self-management tool kit study. Health Promot Pract 2015;16:76574. [CrossRef] 
11. Clark NM, Dodge JA. Exploring self-efficacy as a predictor of disease management. Health Educ Behav 1999;26:72-89. [CrossRef]

12. Lang, CA, Conrad S, Garrett L, Battistutta D, Cooksley WG, Dunne MP, Macdonald GA. Symptom prevalence and clustering of symptoms in people living with chronic hepatitis C infection. J Pain Symptom Manage 2006;31:335-44. [CrossRef]

13. Riazi A, Thompson AJ, Hobart JC. Self-efficacy predicts self-reported health status in multiple sclerosis. Mult Scler 2004;10:61-6. [CrossRef]

14. Chen MF, Wang RH, Hung SL. Predicting health promoting self-care behaviors in people with pre-diabetes by applying Bandura social learning theory. Appl Nurs Res 2015;28:299-304. [CrossRef]

15. Bandura A. Self-efficacy: Toward a unifying theory of behavioral change. Psychol Rev 1977;84:191-215. [CrossRef]

16. Gruber-Baldini AL, Velozo C, Romero S, Shulman LM. Validation of the PROMISÒ measures of self-efficacy for managing chronic conditions. Qual Life Res 2017;26:1915-24. [CrossRef]

17. Stanford Patient Education Research Center. Self-efficacy for managing chronic disease 6-item scale. Available from http:// patienteducation.stanford.edu/research/secd6.html Accessed on March 1, 2017.

18. Fernandez S, Chaplin W, Schoenthaler AM, Ogedegbe G. Revision and validation of the medication adherence self-efficacy scale (MASES) in hypertensive African Americans. J Behav Med 2008;31:453-62. [CrossRef]

19. Ogedegbe G, Mancuso CA, Allegrante JP, Charlson ME. Development and evaluation of a medication adherence self-efficacy scale in hypertensive African-American patients. J Clin Epidemiol 2003;56:520-9. [CrossRef]

20. Freund T, Gensichen J, Goetz K, Szecsenyi J, Mahler C. Evaluating self-efficacy for managing chronic disease: psychometric properties of the six-item self-efficacy scale in Germany. J Eval Clin Pract 2013;19:39-43. [CrossRef]

21. Cicerone KD, Azulay J. Perceived self-efficacy and life satisfaction after traumatic brain injury. J Head Trauma Rehabil 2007;22:257-66. [CrossRef]

22. Lorig K, Chastain RL, Ung E, Shoor S, Holman HR. Development and evaluation of a scale to measure perceived self-efficacy in people with arthritis. Arthritis Rheum 1989;32:37-44. [CrossRef]
23. Schuurmans $H$, Steverink N, Frieswijk N, Buunk BP, Slaets $J P$, Lindenberg $\mathrm{S}$. How to measure self-management abilities in older people by self-report. The development of the SMAS-30. Qual Life Res 2005;14:2215-28. [CrossRef]

24. Gözüm S, Aksayan S. Öz etkililik-yeterlik ölçeğinin Türkçe formunun güvenilirlik ve geçerliliği. Anadolu Hemşirelik ve Sağlık Bilimleri Derg 1999;2:21-35.

25. Gözüm S, Hacıhasanoğlu R. Reliability and validity of the Turkish adaptation of medication adherence self-efficacy scale in hypertensive patients. Eur J Cardiovasc Nurs 2009;8:129-36. [CrossRef]

26. Ünsal A, Kaşıķ̧ı MK. Effect of education on perceived self-efficacy for individuals with arthritis. Int J Caring Sci 2010;3:3-11.

27. Yıldırım F, İlhan IÖ. The validity and reliability of the general selfefficacy scale Turkish form. Turk Psikiyatri Derg 2010;21:301-8.

28. Incirkuş K, Nahcivan N. Validity and reliability of the Turkish version of the self-efficacy for managing chronic disease 6-item scale 2nd International Clinical Nursing Congress, İstanbul, Türkiye, 24-27 Haziran 2015.

29. Budak F. Klinik Liderlik Ölçeğinin Türkçe Geçerlik Güvenilirlik Çalışması: Kamu Hastaneleri Örneği. ACU Sağlık Bil Derg 2017;:85-91.

30. Büyüköztürk Ş. Testlerin Geçerlik ve Güvenirlik Analizlerinde Kullanılan Bazı İstatistikler. Sosyal Bilimler için Veri Analizi El Kitabı 17. Baskı. Ankara; 2012. ss.167-82.

31. Jeong J. Analysis of The Factors and The Roles of HRD in Organizational Learning Styles As Identified By Key Informants At Selected Corporations in The Republic of Korea. Unpublished thesis. USA: Texas A \& M University. Major Subject: Educational Human Resource Development; 2004.

32. Kalaycı Ş. SPSS Uygulamalı Çok Değişkenli İstatistik Teknikleri. Ankara; 2009.

33. Sümer N. Yapısal eşitlik modelleri: Temel kavramlar ve örnek uygulamalar. Türk Psikoloji Yazıları 2000;3:49-74.

34. Cole DA. Utility of confirmatory factor analysis in test validation research. J Consult Clin Psychol 1987;55:584-94. [CrossRef]

35. Kline RB. Principles and Practice of Structural Equation Modeling, 2nd ed. New York: The Guilford Press; 2005.

36. Tezbaşaran, A. Likert Tipi Ölçek Geliştirme Kılavuzu (2. baskı). Türk Psikologlar Derneği Yayını, Ankara; 1997. 